Bull. Mater. Sci., Vol. 17, No. 6, November 1994, pp. 1095-1101. (C) Printed in India.

\title{
Effect of structure on properties of vinyl ester resins
}

\author{
P SIVA, I K VARMA*, D M PATEL ${ }^{\dagger}$ and T J M SINHA ${ }^{\dagger}$ \\ Centre for Polymer Science and Engineering, Indian Institute of Technology, New Delhi \\ 110016 , India \\ ${ }^{\dagger}$ Gujarat State Fertilizers Company Ltd. (Polymer Unit), P.O. Petrofils, Dist Vadodara, \\ Gujarat State, India.
}

\begin{abstract}
The paper describes the synthesis of vinyl ester resins based on diglycidyl ether of bisphenol-A (epoxy equivalent $=450-465 \mathrm{~g} / \mathrm{eq}$ ) (VR resin) and tetrabromobisphenol-A (epoxy equivalent $=380-420 \mathrm{~g} / \mathrm{eq}$ ) (VR-1 resin). The viscosity of styrenated VR resin was higher than VR-1 resin. The effect of styrene and $\alpha$-methyl styrene on curing of VR resins was studied. An increase in styrene from 30 to $50 \mathrm{wt} \%$ resulted in an increase in gel time and a decrease in exothermic peak. Addition of $\alpha$-methyl styrene delayed and depressed the exotherm. The mechanical properties of VR resin sheets and glass fabric reinforced laminates were better than VR-1 resins; whereas LOI of VR-1 was higher. A resin formulation containing $20-30 \mathrm{wt} \%$ of VR:VR-1 showed optimum mechanical properties and LOI.
\end{abstract}

Keywords. Vinyl ester resin; synthesis; mechanical properties.

\section{Introduction}

Methacryloxy or acryloxy derivatives of epoxy resins (vinyl ester resin) are suitable materials for corrosion resistant equipments, body and structural part for land transportation vehicles, electrical insulation, radiation curable inks and coating formulations. Vinyl ester (VE) resins combine the excellent thermal and mechanical properties of epoxy resins with the ease of processing and rapid curing of polyester resins (Kay 1981). The viscosity of neat vinyl ester resins is high, thereby making processing difficult. Hence reactive diluents such as styrene, alkyl methacrylates (Yilgor et al 1985), $\alpha$-methyl styrene are added to the resin which not only help in processing but improve some properties (e.g. strength, \% elongation, hardness, chemical and scratch resistance) and brings down the cost of the resin. The effect of reactive diluent content on properties of VE resins has already been reported (Goel et al 1985; Varma et al 1985).

In our earlier studies we have reported the synthesis and characterization of vinyl ester resins based on diglycidyl ether of bisphenol-A (DGEBA) (Bhatnagar and Varma 1989; Padma et al 1993b) and epoxy novolac resins (Padma et al 1993a). The epoxy equivalent weight of the epoxy resins used were 221 (DGEBA) and $186 \mathrm{~g} / \mathrm{eq}$ (epoxy novolac resin). An epoxy backbone of higher molecular weight is expected to produce greater toughness and resiliency. Therefore it was considered of interest to study the properties of VE resins based on an epoxy resin of higher molecular weight. The flame resistance of VE resins can be improved by incorporation of bromine containing compounds. The present paper reports the synthesis,

*For correspondence. 
characterization and properties of vinyl ester resins based on diglycidyl ether of -bisphenol A/tetrabromobisphenol-A. The effect of reactive diluent content on the curing behaviour was also investigated.

\section{Experimental}

\subsection{Synthesis of vinyl ester resins}

The synthesis of vinyl ester resin was done in a $1 \mathrm{~L}$ three necked flask equipped with a condenser having a $\mathrm{CaCl}_{2}$ guard tube. Air was bubbled through one inlet and a temperature sensor was fixed in another. $183 \mathrm{~g}$ of epoxy resin (Ciba Geigy) (epoxy equivalent $450-465 \mathrm{~g} / \mathrm{eq}$ ), $85 \mathrm{~g}$ of methacrylic acid (GSFC), $80 \mathrm{~mL}$ of methyl ethyl ketone (E. Merck), $85 \mathrm{mg}$ of hydroquinone and $5 \mathrm{~g}$ of quaternary ammonium salt were placed in the flask, which was then heated on a heating mantle maintained at $90-100^{\circ} \mathrm{C}$. The reaction was stopped when the acid number was below ten. The solvent was distilled off and the resin was cooled and stored at $10^{\circ} \mathrm{C}$. This resin has been designated as VR in subsequent discussion.

The synthesis of brominated vinyl ester resin (designated as VR-1) was carried out in a similar manner using $180 \mathrm{~g}$ of diglycidyl ether of tetrabromobisphenol-A (Taiwan) (epoxy equivalent $=380-420 \mathrm{~g} / \mathrm{eq})$, methacrylic acid $(70 \mathrm{~g})$, methyl ethyl ketone $(80 \mathrm{~mL})$, quaternary ammonium salt $(5 \mathrm{~g})$ and hydroquinone $(80 \mathrm{mg})$.

\subsection{Characterization}

The viscosity of vinyl ester resins containing different amounts of styrene (30-50 wt\%) was determined using a Brookfield synchroelectric viscometer equipped with a LV-2 spindle at room temperature. The viscosity of VR: VR-1 resins (weight of VR-1 from 0-40) containing 50\% styrene as reactive diluent were also determined.

Gel time determination of $50 \mathrm{~g}$ resin samples was done at $25 \pm 1^{\circ} \mathrm{C}$ using $1 \mathrm{~g}$ benzoyl peroxide and $1 \mathrm{~g} \mathrm{~N}, \mathrm{~N}$-dimethyl aniline $(2 \%)$ at room temperature. The increase in temperature of the sample as a function of time was measured and gel time was determined by extrapolation.

\subsection{Fabrication of vinyl ester resin sheets and composites}

The sheets were fabricated using styrenated VR, and VR : VR-1 resin, methyl ethyl ketone peroxide $(1 \%), \mathrm{N}, \mathrm{N}$-dimethylaniline $(0.1 \%)$ and cobalt octoate $(0.1 \%)$. The requisite amount of reagents were placed in a $\mathrm{IL}$ beaker and stirred using a mechanical stirrer for $30 \mathrm{~min}$. After filtration (using a high vacuum pump) to remove suspended particles and degassing, the viscous syrup was poured into the toughened glass mould $\left(40 \times 30 \mathrm{~cm}^{2}\right)$ having PVC gasket $(3 \mathrm{~mm})$. The filled glass mould was then kept in an air oven at $80-90^{\circ} \mathrm{C}$ for $3-4 \mathrm{~h}$ for curing. Density of the cured sheet was determined by displacement method according to ASTM D-792, by using a Mettler electronic balance and sample of size $2.5 \times 2.5 \mathrm{~cm}^{2}$.

Glass fabric reinforced vinyl ester resin composites were fabricated using hand lay up technique. Benzoyl peroxide (2\%) and $N, N$-dimethyl aniline $(0.06 \%)$ was 
used as the initiator. The required quantity of vinyl ester resin, styrene and initiator were mixed in a $500 \mathrm{ml}$ beaker. The total quantity of the solution was $130 \mathrm{~g}$. It was then stirred using a mechanical stirrer for complete mixing and filtered. This resin solution was then brush-coated uniformly on the glass fabric of dimension $25 \times 25 \mathrm{~cm}^{2}$. Ten plies were coated with the resin and stacked between steel plates covered with mylar sheets. Initial curing was done at room temperature for $24 \mathrm{~h}$ and then the assembly was placed between the platens of a Carver hydraulic press at $80-90^{\circ} \mathrm{C}$ for $2 \mathrm{~h}$ (pressure $176-180 \mathrm{psi}$ ). Post curing of the laminates was done at $130^{\circ} \mathrm{C}$ for $3 \mathrm{~h}$. After post curing, the laminates were machined to the required dimensions. Residual cure of resin sheets was evaluated by using a Du. Pont 9900 thermal analyzer having a 910 DSC module. The resin content of the laminates was determined by heating a weighed speciman $\left(0.6 \times 0.6 \mathrm{~cm}^{2}\right)$ in a silica crucible in a muffle furnace at $600^{\circ} \mathrm{C}$ for $2 \mathrm{~h}$. The glass fibre was unaffected at this temperature but the resin completely burnt off. The fibres were weighed and resin content evaluated.

Thermal stability of cured resins in nitrogen atmosphere (flow rate $=60 \mathrm{~cm}^{3} / \mathrm{min}$ ) was evaluated using Du Pont 1090 thermal analyzer having a 951 TG module. A heating rate of $10 \mathrm{~K} / \mathrm{min}$ and sample weight of $10 \pm 1 \mathrm{mg}$ was used. TG traces were analyzed for (a) initial decomposition temperature $\left(T_{\mathbf{i}}\right)$ obtained by extrapolation, (b) temperature of maximum rate of weight loss $\left(T_{\mathrm{m}}\right)$ obtained from differential thermogravimetric traces and final decomposition temperature $\left(T_{\mathrm{p}}\right)$. In case decomposition proceeded in two steps, then characteristic decomposition temperature of both the steps were noted, and indicated by writing a suffix 1 or 2 . The $\%$ weight loss in each step was also noted.

The limiting oxygen index (LOI) of resin sheets were determined according to ASTM D-2863. The Stanton Redcroft flammability tester was used for this purpose.

\subsection{Mechanical properties of neat sheet and composites}

An Instron tensile tester model 1121 was used to determine the mechanical properties. The tensile strength of specimen was determined by ASTM D-638-76. The conditions used were guage length $7 \mathrm{~cm}$, full scale load $500 \mathrm{~kg}$, chart speed $200 \mathrm{~mm} / \mathrm{min}$ and cross head speed $10 \mathrm{~mm} / \mathrm{min}$.

Flexural strength was measured according to ASTM D-790-71 using a three point loading system. Specimen having span-to-depth ratio of $32: 1$, width $13 \mathrm{~mm}$ were used. The testing conditions were: cross head speed $10 \mathrm{~mm} / \mathrm{min}$ for sheets and 50 $\mathrm{mm} / \mathrm{min}$ for composite, chart speed $200 \mathrm{~mm} / \mathrm{min}$, full scale load $20 \mathrm{~kg}$ for neat sheets and $50 \mathrm{~kg}$ for composite.

Inter laminar shear strength (ILSS) was determined according to ASTM-D-2344-76. The test conditions employed were: span-to-depth ratio $5: 1$, length-to-thickness ratio $7: 1$, cross head speed $1 \mathrm{~mm} / \mathrm{min}$ and chart speed $100 \mathrm{~mm} / \mathrm{min}$.

\section{Results and discussion}

The structure of VR and VR-1 resins synthesized in the present studies can be depicted as follows: 


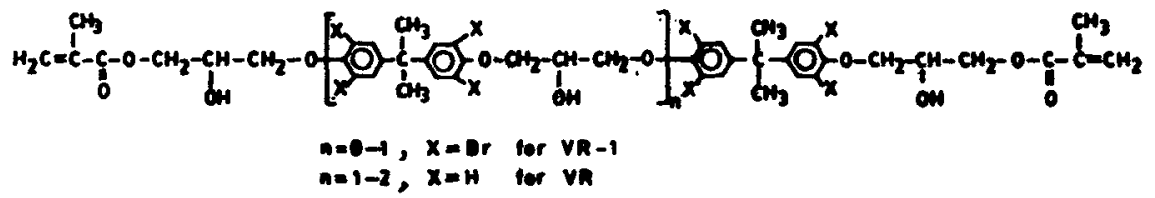

Tuble 1. Brookfield viscosity of styrenated VR and VR : VR-1 resins.

\begin{tabular}{lcccc}
\hline \multirow{2}{*}{$\begin{array}{l}\text { Resin } \\
\text { designation }\end{array}$} & \multicolumn{2}{c}{$\begin{array}{c}\text { Vinyl ester resin } \\
(\% \text { w/w) }\end{array}$} & $\begin{array}{c}\text { Styrene } \\
\text { content } \\
(\% \text { w/w) }\end{array}$ & $\begin{array}{c}\text { Viscosity } \\
\text { (cps) }\end{array}$ \\
\cline { 2 - 4 } & VR & VR-1 & & \\
\hline VR-A & 50 & 0 & 50 & 15.75 \\
VR-B & 55 & 0 & 45 & 20.25 \\
VR-C & 60 & 0 & 40 & 30.50 \\
VR-D & 65 & 0 & 35 & 45.00 \\
VR-E & 70 & 0 & 30 & 78.00 \\
VR-1A & 0 & 50 & 50 & 5.75 \\
VER-P & 40 & 10 & 50 & 13.00 \\
VER-Q & 30 & 20 & 50 & 11.00 \\
VER-R & 25 & 25 & 50 & 10.25 \\
VER-S & 20 & 30 & 50 & 9.25 \\
VER-T & 10 & 40 & 50 & 7.25 \\
\hline
\end{tabular}

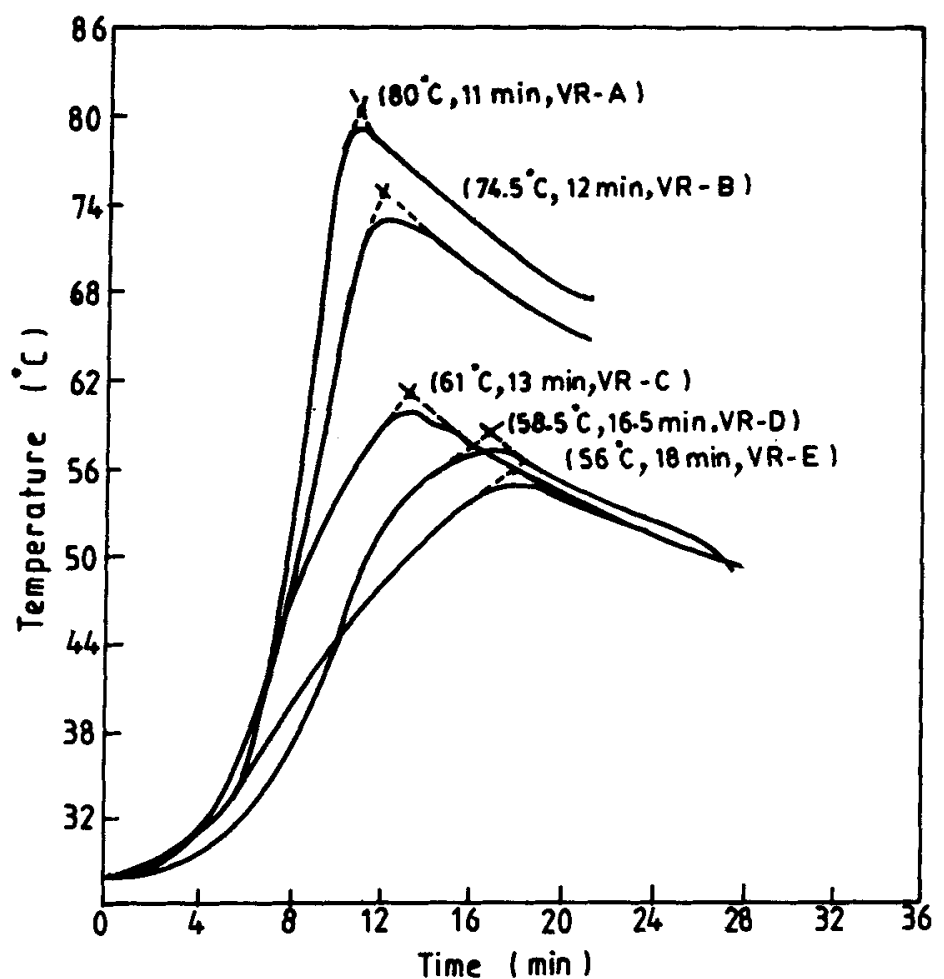

Figure 1. Gel point determination of VR resin in presence of different wt\% of styrene (initiator benzoyl peroxide and $\mathbf{N}, \mathbf{N}$-dimethyl aniline). 
Effect of structure on vinyl ester resins

Table 2. Effect of $\alpha$-methyl styrene ( $\alpha-M S)$ on cure characteristics of styrenated vinyl ester resin.

\begin{tabular}{lcccc}
\hline $\begin{array}{l}\text { VR } \\
(\%, w / w)\end{array}$ & $\begin{array}{c}\text { Styrene } \\
(\%, w / w)\end{array}$ & $\begin{array}{c}\alpha-M S \\
(\%, w / w)\end{array}$ & $\begin{array}{c}\text { Gel time } \\
(\mathrm{min})\end{array}$ & $\begin{array}{c}\text { Exotherm peak } \\
\text { temp. ("C) }\end{array}$ \\
\hline 50 & 50 & 0 & 18 & 56 \\
50 & 48 & 2 & 20 & 51 \\
50 & 45 & 5 & 22 & 43 \\
50 & 40 & 10 & $>8 \mathrm{~h}$ & - \\
\hline
\end{tabular}

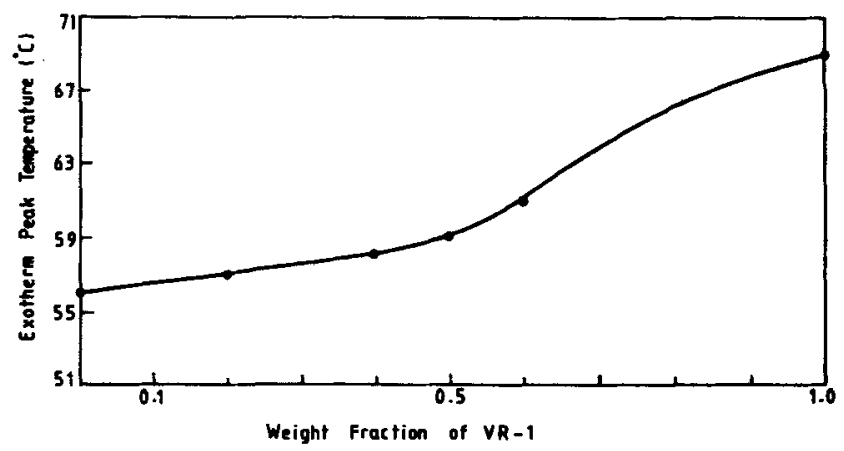

Figure 2. Effect of VR-1 content on exotherm peak temperature of VR:VR-1 resin formulation containing 50 wt\% of styrene (initiators-benzoyl peroxide and N,N-dimethyl aniline).

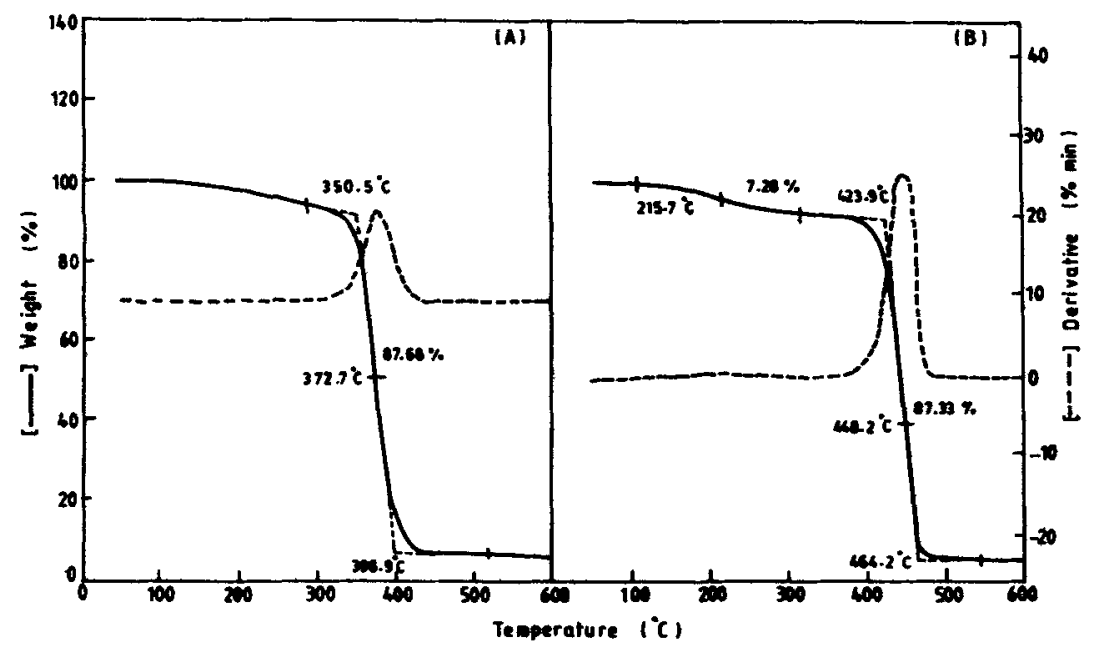

Figure 3. TG traces of (A) VR-1A and (B) VR-A resin sheets in $\mathrm{N}_{2}$ atmosphere. 
Table 3. Thermal behaviour of cured vinyl ester resin sheets.

\begin{tabular}{lccccc}
\hline $\begin{array}{l}\text { Decomposition } \\
\text { temp. (C) } \\
\text { (\% wt loss) }\end{array}$ & VR-A & VER-P & VER-R & VER-T & VR-1A \\
\hline$T_{\text {il }}$ & 160 & 170 & 168 & 150 & - \\
$T_{\text {m1 }}$ & 215 & 230 & 223 & 226 & - \\
$T_{\mathrm{h}}$ & 315 & 290 & 270 & 270 & - \\
$(\%$ wt loss) & $(7.3)$ & $(6.9)$ & $(6.3)$ & $(5.0)$ & - \\
$T_{\text {i2 }}$ & 424 & 377 & 336 & 356 & 350 \\
$T_{\text {m2 }}$ & 448 & 415 & 389 & 378 & 372 \\
$T_{\text {f2 }}$ & 464 & 437 & 410 & 404 & 397 \\
$(\%$ wt loss) & $(87)$ & $(87)$ & $(81)$ & $(88)$ & $(87.7)$ \\
\hline
\end{tabular}

Table 4. Mechanical properties of cured vinyl ester resins.

\begin{tabular}{lccccc}
\hline & \multicolumn{5}{c}{ Property } \\
\cline { 2 - 6 } $\begin{array}{l}\text { Resin } \\
\text { designation }\end{array}$ & $\begin{array}{c}\text { TS } \\
(\mathrm{MPa})\end{array}$ & $\begin{array}{c}\text { TM } \\
(\mathrm{GPa})\end{array}$ & $\begin{array}{c}\text { FS } \\
(\mathrm{MPa})\end{array}$ & $\begin{array}{c}\text { FM } \\
(\mathrm{GPa})\end{array}$ & $\begin{array}{c}\text { Limiting oxygen } \\
\text { index (\%) }\end{array}$ \\
\hline VR-A & 30.78 & 1.05 & 78.18 & 3.42 & 19.9 \\
VER-P & 30.56 & 1.32 & 77.83 & 3.57 & 20.8 \\
VER-Q & 34.08 & 1.53 & $76-88$ & 3.57 & 21.2 \\
VER-S & 35.95 & 1.45 & 75.76 & 3.69 & 22.4 \\
VR-1A & 34.81 & 1.48 & 67.70 & 3.55 & 23.0 \\
\hline
\end{tabular}

Table 5. Mechanical properties of vinyl ester resin composites.

\begin{tabular}{lcccc}
\hline \multirow{2}{*}{$\begin{array}{l}\text { Resin } \\
\text { designation }\end{array}$} & $\begin{array}{c}\text { Resin } \\
\text { content }\end{array}$ & $\begin{array}{c}\text { FS } \\
(\mathrm{MPa})\end{array}$ & $\begin{array}{c}\text { FM } \\
\text { (GPa) }\end{array}$ & $\begin{array}{c}\text { IISS } \\
\text { (MPa) }\end{array}$ \\
\hline VR-A & 37.71 & 377.16 & 21.96 & 38.42 \\
VER-P & 37.25 & 418.80 & 21.28 & 39.79 \\
VER-R & 38.09 & 353.92 & 21.05 & 33.33 \\
VER-T & 40.37 & 308.72 & 20.24 & 26.71 \\
VR-1A & 39.20 & 323.12 & 20.51 & 28.68 \\
\hline
\end{tabular}

The viscosity of VR containing different weight\% of styrene and of VR: VR-1 resin containing $50 \mathrm{wt} \%$ of styrene are given in table 1 . As expected, the viscosity of VR resin decreased by increasing styrene content in the formulation. The viscosity of VR-A resin (containing $50 \mathrm{wt} \%$ of styrene) was almost three times that of VR-1A resin (50 wt\% styrene).

Gel time determination studies of VR resin in presence of different weight fraction of styrene are shown in figure 1. An increase in styrene content resulted in an increase in gel time and a decrease in exotherm peak temperature. Styrene, being a monofunctional monomer, reduces the cross-link density, thereby increasing the time for onset of gelation. A decrease in exotherm peak temperature and an increase 
in time of gelation was observed by partial replacement of styrene in VR-A resin by $\alpha$-methyl styrene ( $\alpha$-MS) (table 2 ).

Therefore from the gel time studies, it can be concluded that the gelation is reduced in presence of $\alpha-M S$. The lower reactivity of $\alpha$-methyl styrene may be explained on the basis of the greater stability of the tertiary propagating radical and hence reduced tendency for propagation.

The gel time decreased from 18 to $14 \mathrm{~min}$ by addition of VR-1 resin to VR (styrene content $50 \mathrm{wt} \%$ ). The exotherm peak temperature increased from $56^{\circ} \mathrm{C}$ to $69^{\circ} \mathrm{C}$ (figure 2 ).

The density of cured specimen of VR-A and VR-IA were found to be 1.115 $\mathrm{g} / \mathrm{cm}^{3}$ and $1.25 \mathrm{~g} / \mathrm{cm}^{3}$ respectively.

The DSC scans of neat resin sheets showed absence of exothermic transition indicating thereby the absence of residual monomers/oligomers in the cured samples. These samples were stable up to $200^{\circ} \mathrm{C}$. A weight loss of $5-8 \%$ was observed above this temperature (figure 3). However the major weight loss was above $420^{\circ} \mathrm{C}$ in VR-A and above $350^{\circ} \mathrm{C}$ in VR-1A. The lower decomposition temperature in VR-1A is due to the scission of $\mathrm{C}-\mathrm{Br}$ bond which is thermally labile. The TG results of various resin samples are summarized in table 3.

The mechanical properties and oxygen index (LOI) of the neat sheets are given in table 4. The tensile strength of VR-1A was higher than VR-A. The tensile strength and LOI of VER-Q and VER-S resin formulation were found to be better than VR-A. Flexural strength of VR-A was higher than VR-1A. This may be due to high molecular weight epoxy resin used for the synthesis of VR-A resin. The limiting oxygen index of VR-1A was highest and it decreased by increasing VR-A content in the formulation. These results thus indicate that VER-Q and VER-S resins have good mechanical properties and flame resistance.

The glass fabric reinforced VR samples having $38.5 \pm 1.5 \%$ resin, exhibited good properties (table 5). The flexural strength, flexural modulus and ILSS was higher in VR-A. An increase of VR-1A in the resin formulation resulted in a decrease in ILSS and flexural properties.

Thus the vinyl ester resin based on high molecular weight epoxy resin have better flexural strength and modulus. Addition of $20-30 \mathrm{wt} \%$ of brominated vinyl ester resin to this VR resin increases the LOI without affecting the mechanical properties.

\section{References}

Bhatnagar R and Varma I K 1989 J. Therm. Anal. 351241

Goel T C, Tripathi A, Rao B S, Choudhary M S, Choudhary V and Varma 1 K 1985 J. Appl. Polym. Sci. 801491

Kay R 1981 in Fibre composite hybrid materials (ed.) N L Hancox (London: Applied Science Pub.) pp 35-51

Padma G, Varma I K, Sinha T J M and Patel D M 1993a Angew. Makromol. Chem. 211157

Padma G, Varma I K, Sinha T J M and Patel D M 1993b Angew. Makromol. Chem. 21267

Varma I K, Rao B S, Choudhary M S, Choudhary V and Varma D S 1985 Angew. Makromol. Chem. 130191

Yilgor I, Yilgor E, Banthia A K, Wilkes G L and McGrath J E 1985 Angew. Makromol. Chem. 130 191 